\title{
Elastofibroma Dorsi: Review of Literature with Radiological
}

\section{Approach}

\author{
Gil Serrano PE${ }^{1}$, Echeverri Palacio J², Daza Cajas G², Vasquez AY³, \\ Ordoñez Salazar LM4 , Ortiz Quijano MC4 and Chaustre Soledad JE5* \\ ${ }^{1}$ Medical Radiologist, CES University, Colombia \\ ${ }^{2}$ Medical Radiologist, Imbanaco Medical Center, Colombia \\ ${ }^{3}$ Resident Physician of Radiology, Universidad De La Sabana, Colombia \\ ${ }^{4} \mathrm{MD}$ intern, Pontificia Universidad Javeriana, Colombia \\ ${ }^{5} \mathrm{MD}$ intern, La Sabana University, Colombia
}

*Corresponding author: Jose E Chaustre Soledad, MD intern, Universidad de La Sabana, Bogotá, Colombia, Calle 142 \#11-50, Tel: +57 318-358-7572; Email: jose.chaustre@hotmail.com

\section{Abstract}

Elastofibroma Dorsi is a benign soft tissue tumor, that is rare; commonly located in the scapula, and found more frequently presented in women. Its etiology is unknown, but is mostly associated to the result of mechanical friction between two musculoskeletal surfaces. It is frequently manifestated as an asymptomatic mass, with variable size and location. Its diagnosis is clinical, however there are numerous diagnostic aids, of which the most relevant is magnetic resonance for its ability to characterize the lesion. The differential diagnoses are lipoma, liposarcoma, sarcoma, hemangioma, desmoid tumor and osteosarcoma. Its definite treatment is surgical resection.

Keywords: Elastofibroma; Superficial Back Muscles; Soft Tissue Neoplasms; Surgical Procedures; Operative Magnetic Resonance Imaging

\section{Introduction}

The elastofibroma dorsi is a benign soft tissue tumor, that is rare; with a $2-24 \%$ prevalence in the elderly [1], it has a slow growing rate, and its composition is of fibroelastic and adipose tissue. Mainly located in the infrascapular región [2]. Its etiology is unknown, nevertheless, some hypothesis have been suggested among which are considered: that it develops due to a reactive process, result of the mechanical friction between the scapula and the rib cage that generates hyperplasia of elastic fibers [3]. Commonly, presented in patients with history of high impact manual activities $[4,5]$.
It was first described by Jarvi \& Saxen in 1953 and reported in 1961 [6,7]. It mainly affects patients with an average age of 60 years, nevertheless it may be present in childhood [8,9] and is more frequent in women with a $13: 1$ ratio $[3,7]$. Its variable in size and oscilates between 1.5 to $20 \mathrm{~cm}$ in its largest diameter $[3,4]$. It may be unilateral o bilateral; when unilateral they are predominanly presentented in the right subscapular region, between the thoracic wall, the anterior serratus and the latissimus dorsi of the back at the height of the sixth and eighth costal arches (Figure 1), and usually, may be adhered to the periostium of these bones. In $60 \%$ of 


\section{Clinical Radiology \& Imaging Journal}

cases it is presented bilaterally, this being a suggestive finding for the diagnosis of elastofibroma [4,7] (Figure 2). Some less common locations are: orbit, deltoid muscle, axilla, olecranon, anterior and lateral thorax, the space between the scapular spines, area of the greater trochanter and ischial tuberosity, femoral fascia lata, feet, tricuspid valve, stomach and omentum, which represent less than $1 \%[10,11]$.
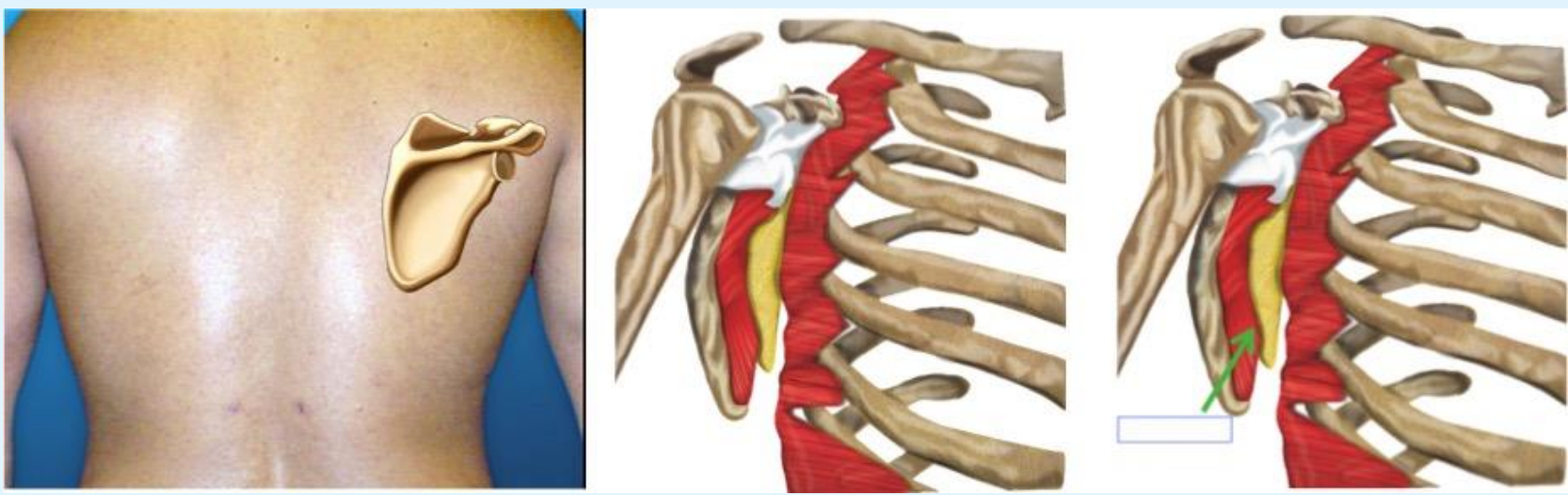

Figure 1: On physical examination, the lesion is usually well circumscribed and is not attached to the skin, however it is difficult to define it with respect to neighboring structures. Normally, when the upper limb is mobilized, the tumor shifts and becomes more palpable and / or more painful. Large tumors can simulate winged scapula by elevating it.

Upon physical examination, it appears as a soft, elastic, firm, mobile, not adhered to deep tissue planes, painless mass; and without evidence of skin alterations [12]. Its size may be augmented by rotational movements of the gleno-humeral articulation. When they are large sized they may simulate a winged scapula $[13,14]$.
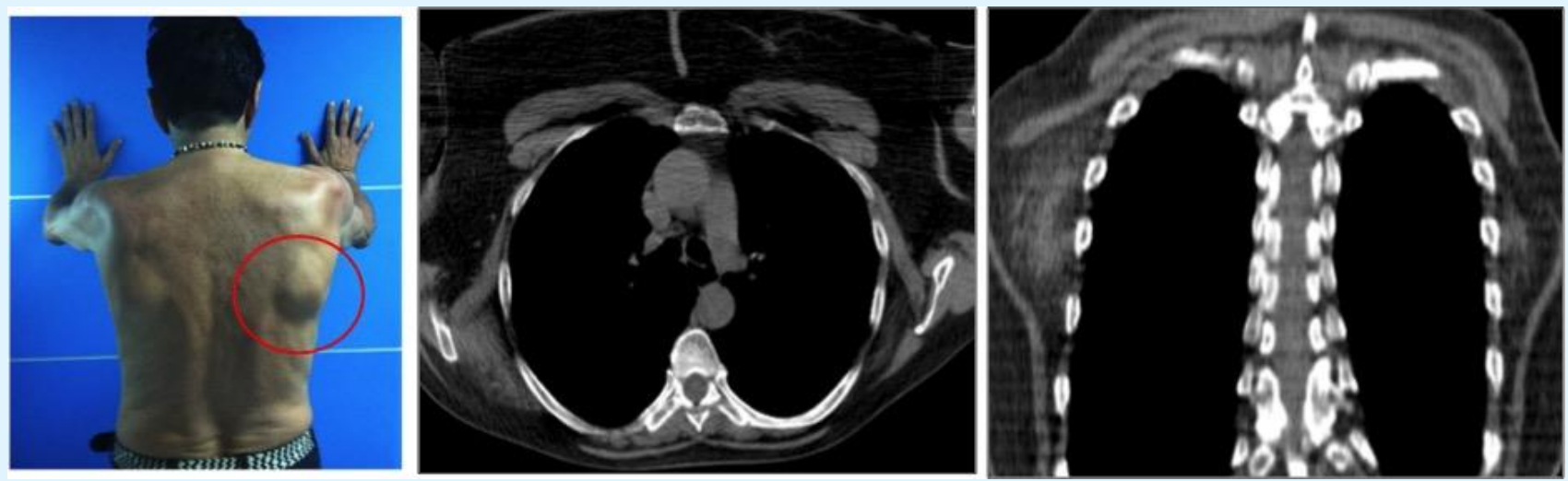

Figure 2: Patient of 55 years of age with bilateral subscapular mass, of right predominance, 5 years of evolution, not painful, of slow growth. Axial tac: mass not encapsulated, located towards the lower edge of the right scapula, with attenuation similar to that of the muscle, without evidence of calcifications, or compromise of the adjacent bony structures. Coronal reconstruction: nonencapsulated mass, located towards the lower edge of the right scapula, with attenuation similar to that of skeletal muscle. Does not compromise adjacent bone structures. It does not present calcifications.

Half of the patients are asymptomatic [11]. Nevertheless if clinical manifestations are present they are associated to diameters superior that $5 \mathrm{~cm}$. A painful and rigid mass that may be associated to discomfort and limitation in the movements of the articulation, associated to a scapular click that in some occasions may present 


\section{Clinical Radiology \& Imaging Journal}

edema, when presesented as a subscapular lesion. It may be confused with a rotator cuff tear or subacromial bursitis. Its treatment is complete surgical resection. Its has low recurrence and is associated with incomplete resection $[8,15]$.

\section{Etiology and Fisiopathology}

Numerous hypothesis have been suggested in regards to its pathogenesis. One third of the patients have previous family history, which suggests a genetic predisposition, being associated to chromosomic changes and systemic enzymatic defects that produce an alteration in the development of elastic tissue $[14,16]$. Also, it has been related to vascular insufficiency due to microangiopathic damage [17].

The most accepted and reported theory is associated with repetitive mechanical microtraumatisms that are generated by the friction between the scapula and the rib cage; these produce reactive changes in the proliferation of fibroblasts, preceded by hyperplasia or metaplasia, that degenerates the collagen fibers $[15,18]$.

\section{Pathological Anatomy}

Macroscopic findings: It is observed as a heterogeneous lesion, not encapsulated, irregular, of elastic consistency, with white and yellow bands, that reflect the overproduction of connective and adipose tissue, generally greater than $5 \mathrm{~cm}$ [8].
Microscopic findings: Lesions composed of hyalinized tissue: eosinofilic collagen, with sinusoidal contours, intertwined with fibroblasts and islets of mature adipose tissue of different sizes [6]. The elastic fibers are degenerated, with an appearance of small linear globules [16], under a Van Gieson stain, the collagen fibers are visualized as bands that range from a brown to black coloring [8].

\section{Imaging Studies}

Magnetic Resonance Imaging: It is considered the best non invasive diagnostic tool due to the pattern evidenced by the alternance between the adipose and the fibrous tissue, a well as establishing a location that is characteristic to the lesión [11]. Visualized as a semilunar soft tissue mass, heterogenous, of poor defined borders, with a greater length in its caudal to skull axis, it may be adjacent to bony structures that may be intact, without infiltration to the thoracic wall $[17,19,20]$. In T1 sequences, the mass is observed to be isointense in relation to the muscle, with areas of a fascicular pattern, curved, and these last ones are hyperintense; similar to subcutaneous tissue. In T2 sequences, of intermediate signaling, it is hypointense and isointense in relation to the muscle with linear areas of high intensity of signal due to the fat component [5]. It presents variable uptake of the intravenous contrast médium [4,11], without presence of a nodular uptake [7] (Figure 3).
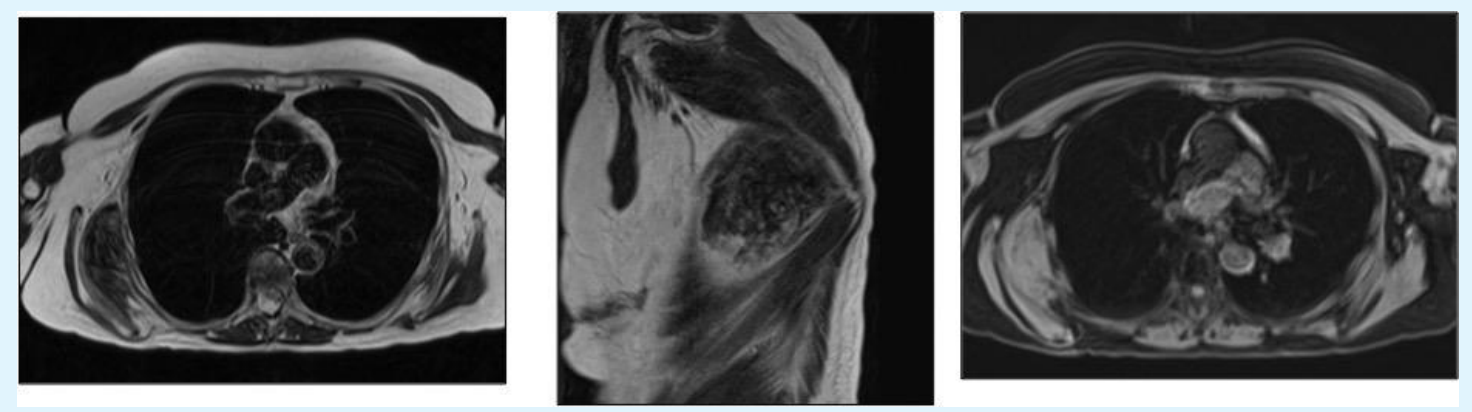

Figure 3: Axial T2: A mass is identified, with well-defined edges, relatively isointense to the muscle in T2 sequences with linear areas of high signal intensity per fatty component, located towards the lower pole of the right scapula. They are located between the thoracic wall, the anterior serratus, and the latissimus dorsum. Coronal T2: Mass is identified, with well-defined edges, relatively isointense to the muscle in T2 sequences with linear areas of high signal intensity by fat component, located towards the lower pole of the right scapula. They are located between the thoracic wall, the anterior serratus, and the latissimus dorsum. Axial T1 fat sat: Mass of well defined edges, predominantly hyperintense in T1 fat sat sequences, with some hypointense areas in relation to small foci of fat, located towards the lower pole of the right scapula. 


\section{Clinical Radiology \& Imaging Journal}

Computed axial tomography: It is less sensitive than MRI for the visualization of adipose tissue, and may be sporadically visualized as a homogenous mass and not establish a concluding diagnosis [11]. It is observed as a mass with soft tissue attenuation, similar to muscle density, poorly defined, heterogenous, with evidence of lineal immaging that are intercalated with low densities, suggestive of fat striations with a greater axis on the skullcaudal axis. In smaller sized lesions, their manifestation is homogenous and hypodense with respect to the adjacent muscle; this finding is associated with the level of maturity in the adipocytes $[7,6]$. In patients in which this study has been performed for tracking pulmonary parenchyma pathology, a $2 \%$ prevalence has been found in those older than 60 years of age [14]. The tomography allows us to discard bone involvement, as well as presence of calcifications [1] (Figure 2).

Ultrasound: It is evidenced as a heterogenous, oval mass, with ecogenic appearance due to the great number of acoustic interphases and ecogenic lines; corresponding to fibrous and fat tissue respectively (Figure 4). Upon doppler color evaluation the presence of blood flow inside the lesion may be identified $[7,21]$.
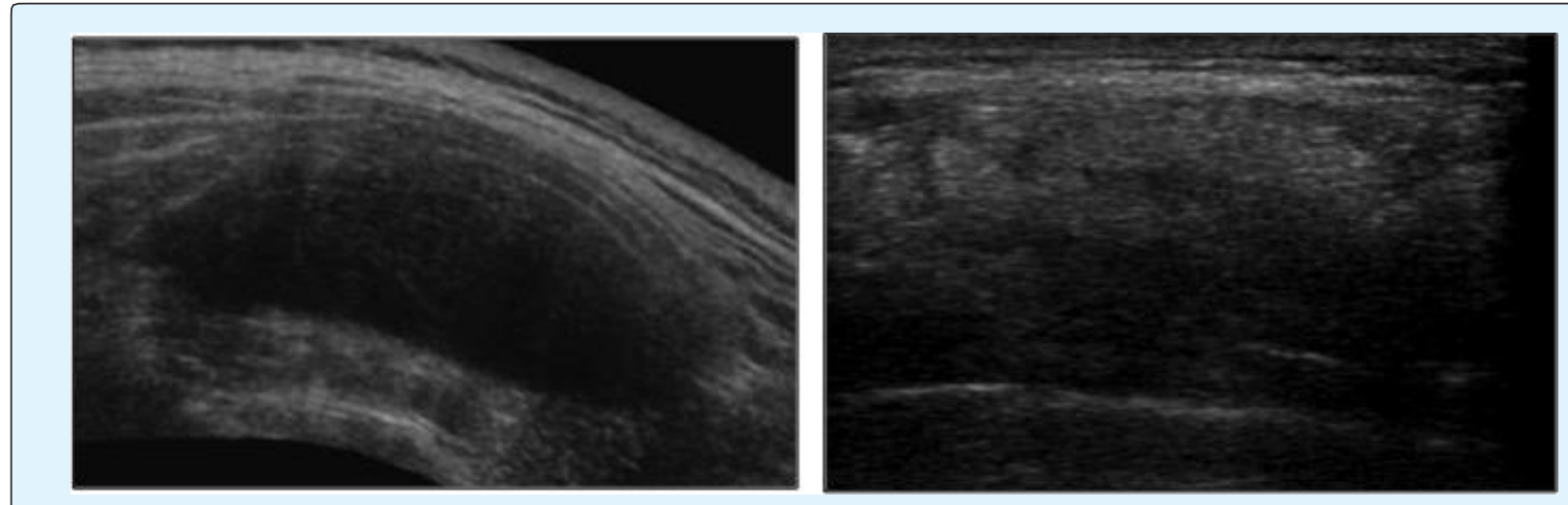

Figure 4: In ultrasound, the elastofibroma manifests itself in a well-defined multilayer pattern; some are hypoechoic and linear due to the interposition of fat interspersed with ecogenic fibroelastic tissue.

Chest X-ray: Is the least common imaging method used for diagnosis; given that it is not easily visualized, it is read as unremarkable; or in some cases, may be seen as a soft tissue mass with extrathoracic or supscapular location, as well as an increase in the space between the scapula and the rib cage [17] (Figure 5).

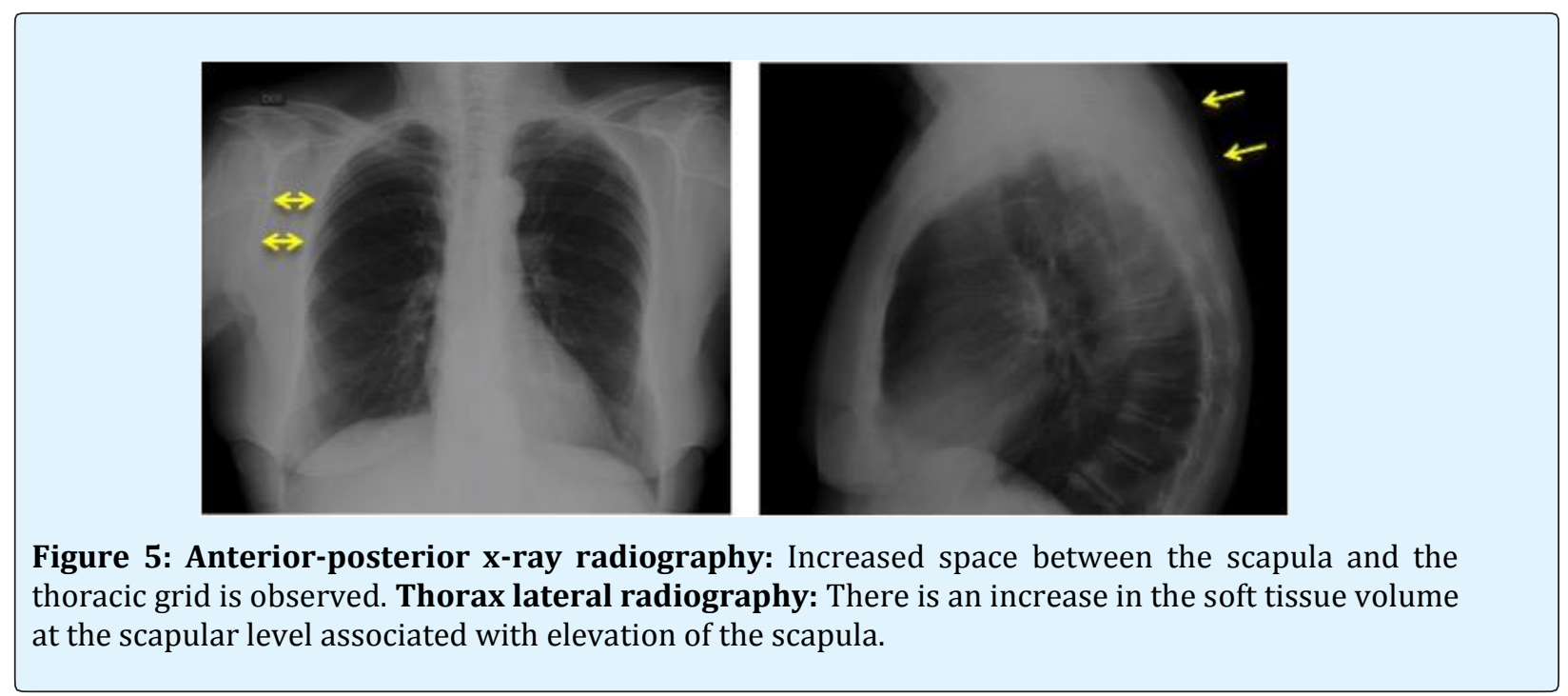




\section{Clinical Radiology \& Imaging Journal}

\section{Differential Diagnoses}

\section{Osteochondroma}

Represents 20 to $50 \%$ of benign bone tumors, being the most common one. It is composed of corticomedullary bone with hyaline cartilage. Most commonly located in long bones, in the appendicular skeleton; of predominance in the knee, femur and humerus, less frequently in flat bones such as the scapula and the hip [22]. Its presence is associated to cartilaginous exostosis that may produce aesthetic and bone deformity as well as articular disfunction. It may be associated with a autosomal dominant syndrome that produces severe lesions (multiple, uncommon) or may be presented as a solitary mass. A 3 to $5 \%$ are malignized when there is family inheritance versus only $1 \%$ in solitary osteochondromas. Upon MRI it is observed in T1 sequence, low intensity of signal due to its high water content in non mineralized regions; and in contrast in T2 sequences it is visualized with hyperintensity of the signal [23] (Figure 6).
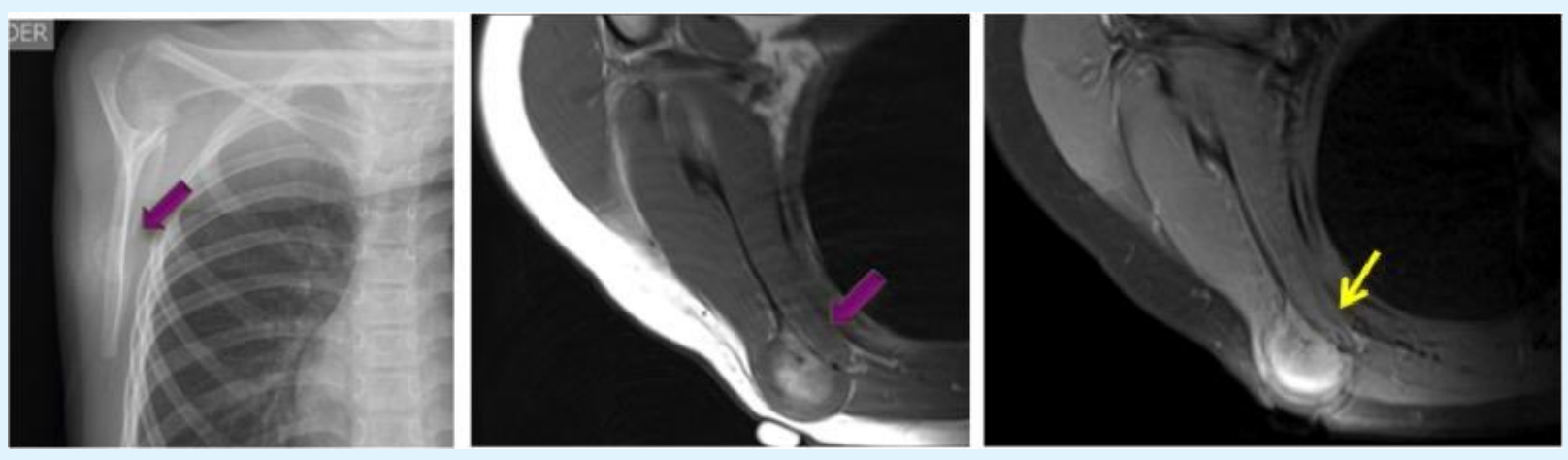

Figure 6: Osteochondroma. A 7-year-old patient who consulted for a non-painful mass in the right scapular region. Simple lateral projection of scapula; radiopaque image, nodular dependent on the body of the right scapula, with smooth and defined edges. T1; with scapular-dependent nodular body image of intermediate intensity. T2 contrasted with fat saturation; with hyperintense image, which increases with contrast enhancement, with peripheral band that could correspond to perichondrium.

\section{Lipoma}

It is the most common soft tissue tumor in adults, composed primarily of adipose tissue. It can develop in fat or muscular planes [5]. Upon MRI it is observed as a homogenous, encapsulated mass, with the same intensity as subcutaneous tissue in all the sequences. In T1 sequence it is observed as hyperintense and in T2 sequences as isointense, relative to subcutaneous tissue; with thin septums, muscular fibers, blood vessels and areas of necrosis with septums in its interior and uptake of contrast médium [24]. Most of the times contrast medium is not required; given that its morphologic characteristics are sufficient for it to be identified [2].

\section{Sarcoma}

Tumor of mesenchymal origin that represents approximately $1 \%$ of all malign tumors. It presents iself as painless mass, localized approximately in $75 \%$ of cases in the extremities and in other locations such as the thoracic wall and the retroperitoneum [25]. It is mainly composed of soft tissue and is located in deep planes. Many subtypes exist and their difference depends on its observation as a mass with poorly defined borders o surrounded by a capsule; it may also infiltrate adjacent structures, generally when its size exceeds $5 \mathrm{~cm}$ [26]. In $\mathrm{T} 1$ sequences it is visualized as a heterogenous lesion, due to its fat and muscular content; and is hyperintense in T2 sequences due to its high water content [5,20,27]. Upon the administration of contrast medium it presents a heterogenous enhancement [5] (Figure 7).

Soft tissue sarcomas are a heterogenous group of malign neoplasms of mesenquimal origin that are developed from mature muscle and fat tissue. They represent $7 \%$ of al infantile tumors in children less than 15 years of age. From these, $60 \%$ are rhabdomiosarcomas, being the most prevalent tumor. It may grow in any part of the body, nevertheless the most common areas are in the head, neck, genitourinary system and extremities [28] (Figure 7). 


\section{Clinical Radiology \& Imaging Journal}
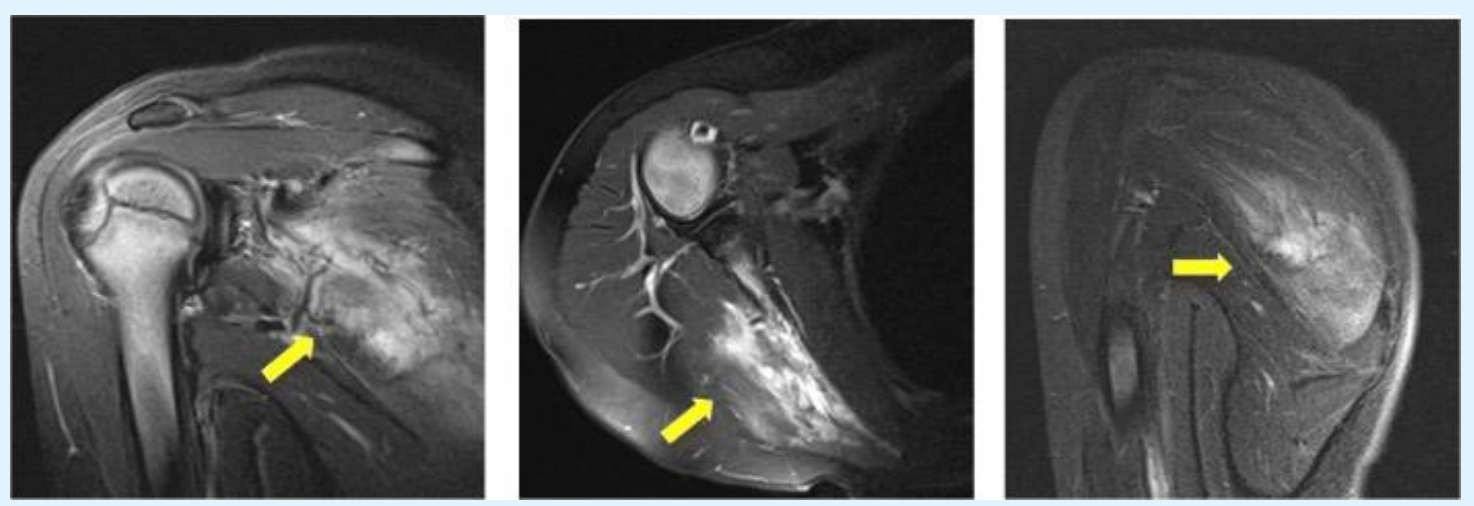

Figure 7: Male patient of 8 years with painful right scapular mass of rapid growth. Bx was performed that reported soft tissue sarcoma. Magnetic resonance $\mathbf{t} 1$ with greasy saturation and contrast: Highly vascularized mass infiltrating the supra and infraspinatus that corresponds to a rhabdomyosarcoma.

\section{Osteosarcoma}

A malign mesenchymal tumor, with osteoblastic, cartilaginous and fibroblastic cells. It is originated in the periosteum. Its appearance may be associated with radiation or history of previous trauma [25]. It is visualized as a heterogenous mass with well defined borders. In T1 sequences it is hypointense in relation to muscle, similar to the appearance of the bone cortex; in $\mathrm{T} 2$ enhanced sequences it has a heterogenous signal due to the presence of necrosis and hemorrage, with enhancement secondary to the contrast medium and restricted in the diffusion sequences [29].

\section{Chondrosarcoma}

It is a malign tumor composed of cells that produce a cartilaginous matrix. The primary chondrosarcoma is the third malign primary tumor of the bone, and it consitutes a 20 to a $27 \%$ of all the primary malign neoplasias of the bone. They may be primary in the $80 \%$ of cases but may also be secondary due to the malignization of benign preexisting tumors (enchondroma or osteochondroma) [30]. It presents itself between the second and the fourth decade of life and is more common in men, their course is slow and painless. Its size may vary from 4 to $20 \mathrm{~cm}$ [31].

Commonly, it is located in the anterior thoracic wall, superior to the fifth intercostal arch. In T1 sequences it is visualized as a mass, with poorly defined borders, hypointense in areas of mineralization surrounded by cartilage, that varies from iso to hypointense. In T2 sequence a hypointensity is observed in the area of mineralization with a hyperintense halo that is characteristic of cartilage [2]. Also, the radiography and tomography may show an expansive lesion in the medullary cavity, with destruction of the cortex and calcifications in the form of coma, pop corn or anular $[9,6,23]$ (Figure 8).
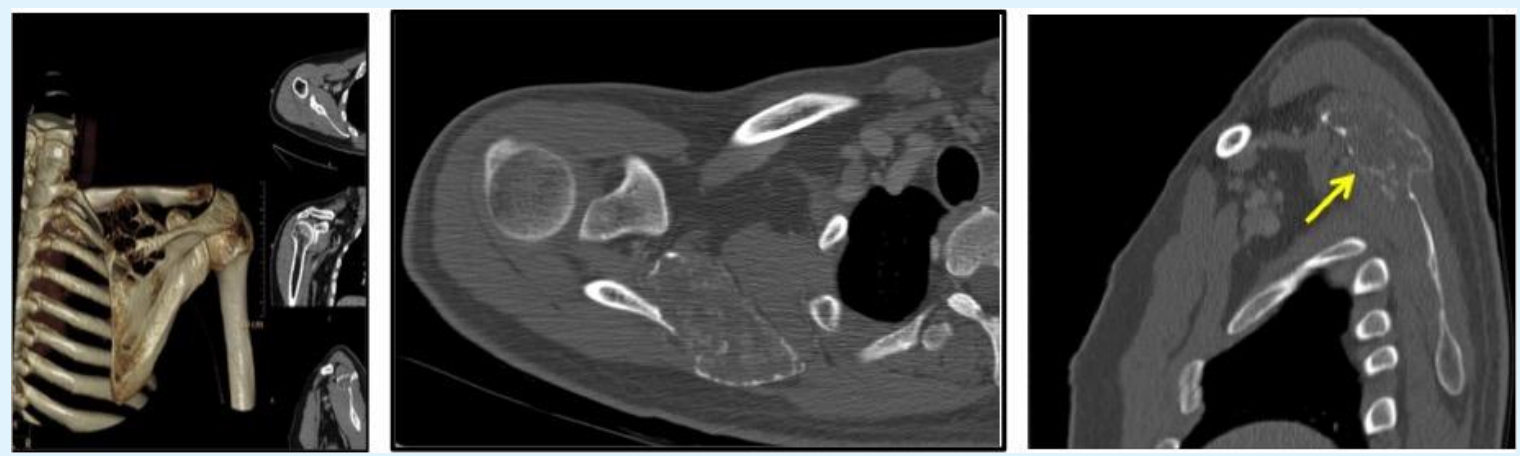

Figure 8: Chondrosarcoma. Male patient of 55 years with painful mass in scapula of rapid growth. Simple tomography of the right shoulder with axial, sagittal and volume rendering reconstruction. With finding of an expansive lesion, with destruction of the scapula-dependent cortical body indicated by the yellow felcha, also with multiple calcifications in its interior. 


\section{Clinical Radiology \& Imaging Journal}

\section{Liposarcoma}

Second most common tumor of soft tissues, malign, composed of adipose tissue and non adipose cellular areas; in magnetic resonance it is visualized as a mass with fatty content and non lipomatose components, with thick septums (greater than $2 \mathrm{~mm}$ ), nodular non adipose areas and calcifications; posterior to the administration of contrast medium it has a heterogenous uptake. In T1 enhanced sequences it is observed as a hyperintense, nevertheless this finding may be variable according to the fat tissue content and in the $\mathrm{T} 2$ sequences is isointense in the subcutaneous tissue $[5,32]$. It may produce bone destruction and in some occassions may be associated to a methastatic involvement [2].

\section{Hemangioma}

Is the most common benign vascular tumor of soft tissues. It is composed of vascular structures, smooth muscle, fibrous tissue and is occasionally associated to the presence of thrombi. In T1 sequences is isointense and in the periphery is characteristic of having fibrous and vascular tissue. Occasionally it has areas of high intensity of signal due to the presence of intralesional fat tissue, and in T2 enhanced sequences it appears as a hyperintense mass that is multilobulated of grape cluster appearance; upon the administration of contrast medium it has a peripheral uptake with a centripetal filling [33].

\section{Desmoid}

Also called deep fibromatoses is a malign neoplasia of mesenchymal origin. It is rare, produced due to the proliferation of fibroblastic cells from the fascia or the muscular aponeurosis. They are locally agressive tumors. On MRI, in T1 enhanced sequences it has low intensity of signal, and in $\mathrm{T} 2$ sequences it also has low intensity of signal that is characteristic of fibrous tissue and poor cellular content. It is associated with the presence of hyperintense banding due to the water content and with contrast medium may vary from moderate to intense enhcancement; generally in the lineal banding along the fascia [9].

\section{Treatment}

The treatment of choice is surgical resection when the lesion is symptomatic. During the surgical procedure the lesion may be adhered to muscular planes and even to the periosteum; thus, the excision must be wide, including skin, deep and superficial subcutaneous tissue [14]. Ocassionally, when its size exceeds $5 \mathrm{~cm}$ and it has a marked enhancement upon intravenous contrast medium; this may suggest malignancy, therefore, may require further pathologic studies. Incomplete surgical resection increases the probability of recurrence. None have been reported of transformation to malignancy [11].

\section{Conclusion}

The elastofibroma is a benign tumor composed of lipidic material and fibrous tissue. Its diagnosis is oriented by the presence of a soft tissue mass that is bilateral, of typical location in the subscapular region, of slow growth and frequently presented in adults. The definitive diagnosis is made with MRI in most of the cases, without the need of performing a confirmatory histopathologic exam. It is important to establish the differential diagnosis with other lesions such as a sarcoma, a liposarcoma and hemangiona; since not all masses in the subscapular region correspond to an elastofibroma.

\section{References}

1. Braham E, Hergli I, Boudaya MS, Ismail O, AyadiKaddour A, et al. (2013) Elastofibroma of scapula: a case report and literature review. Ann Transl Med 1(3): 31.

2. Nam SJ, Kim S, Lim BJ, Yoon CS, Kim TH, et al. (2011) Imaging of primary chest wall tumors with radiologicpathologic correlation. Radiographics 31(3): 749-770.

3. Oueslati S, Douira-Homsi W, Bouaziz MC, Zaouia K (2006) Elastofibroma dorsi : A report on 6 cases. Acta Orthop Belg 72(2): 237-242.

4. Karagülle AT, Erden I, Ayse E, Karada D (2002) Elastofibroma Dorsi: Magnetic Resonance Imaging Findings in Two Cases. J Ankara Med Sch 56(1): 4548.

5. O'Connor EE, Dixon LB, Peabody T, Stacy GS (2004) MRI of cystic and soft-tissue masses of the shoulder joint. AJR Am J Roentgenol 183(1): 39-47.

6. Kransdorf MJ, Meis JM, Montgomery E (1992) Elastofibroma: MR and CT Appearance with Radiologic-Pathologic Correlation. AJR Am J Roentgenol 159(3): 575-579.

7. Ochsner JE, Sewall SA, Brooks GN, Rashmi A (2006) Elastofibroma Dorsi. RadioGraphics 26(6): 18731876.

8. Daigeler A, Vogt PM, Busch K, Pennekamp W, Weyhe D, et al. (2007) Elastofibroma dorsi-differential 


\section{Clinical Radiology \& Imaging Journal}

diagnosis in chest wall tumours. World J Surg Oncol 5: 15.

9. Dinauer PA, Brixey CJ, Moncur JT, Fanburg-Smith JC, Murphey MD (2007) Pathologic and MR Imaging Features of Benign Fibrous Soft-Tissue Tumors in Adults. RadioGraphics 27(1): 173-187.

10. Hammoumi ME, Qtaibi A, Arsalane A, Oueriachi FE, Hassane KE (2014) Elastofibroma dorsi: Clinicopathological Analysis of 76 cases. Korean J Thorac Cardiovasc Surg 47(2): 111-116.

11. Malghem J, Baudrez V, Lecouvet F, Lebon C, Maldague $B$, et al. (2004) Imaging study findings in elastofibroma dorsi. Joint Bone Spine 71(6): 536-541.

12. Kourda J, Kaddour AA, Merai S, Hantous S, Miled KB, et al. (2009) Bilateral elastofibroma dorsi. A case report and review of the literature. Orthop Traumatol Surg Res 95(5): 383-387.

13. Tomasone A (2015) Viñeta clínica Elastofibroma dorsi: reporte de un caso. Evid Act Práct Ambul 18(3): 97-98.

14. De Oliveira BAV, Rosenfeld A, Yanaguizawa M, Zaia RP, Natour J, et al. (2009) Imaging assessment of the scapular girdle elastofibromas. Rev Bras Reumatol 49(3): 324-327.

15. Go PH, Meadows MC, Marie BE, Chamberlain RS (2010) Elastofibroma dorsi: A soft tissue masquerade. Int J Shoulder Surg 4(4): 97-101.

16. Findikcioglu A, Kilic D, Karadayi Ş, Canpolat T, Reyhan M, et al. (2013) A thoracic surgeon's perspective on the elastofibroma dorsi: A benign tumor of the deep infrascapular region. Thorac Cancer 4(1): 35-40.

17. Mahnut T, Kurul CI, Ismail, Gönül II, Memis L, et al. (2014) Exercise-Induced Elastofibroma Dorsi. Eurasian J Pulmonol 16: 47-49.

18. Tsikkinis C, Balamoti S, Grigoropoulos $P$, Papanastasiou G, Birtsou M, et al. (2014) Elastofibroma dorsi. J Balk Union Oncol 19(2): 573576.

19. Yu JS, Weis LD, Vaughan LM, Resnick D (1995) MRI of Elastofibroma Dorsi. J Comput Assist Tomogr 19(4): 601-603.
20. Mullan CP, Madan R, Dickenson BT, Qian X, Jacobson FL, et al. (2011) Radiology of chest wall masses. Am J Roentgenol 197(3): 460-470.

21. Bianchi S, Martinoli C, Abdelwahab IF, Gandolfo N, Derchi LE, et al. (1997) Elastofibroma Dorsi: Sonographic Findings. Am J Roentgenol 169(4): 11131115.

22. de Souza AM, Bispo Jr RZ (2014) Osteochondroma: ignore or investigate? Rev Bras Ortop 49(6): 555-564.

23. Murphey MD, Choi JJ, Kransdorf MJ, Flemming DJ, Gannon FH (2000) Imaging of Osteochondroma: Variants and Complications with RadiologicPathologic Correlation. RadioGraphics [Internet]. 20(5): 1407-1434.

24. Gaskin CM, Helms CA (2004) Lipomas, Lipoma Variants, and Well-Differentiated Liposarcomas (Atypical Lipomas): Results of MRI Evaluations of 126 Consecutive Fatty Masses. Am J Roentgenol 182(3): 733-739.

25. Vliet van M, Kliffen M, Krestin GP, Dijke CF (2009) Soft tissue sarcomas at a glance: Clinical, histological, and MR imaging features of malignant extremity soft tissue tumors. Eur Radiol 19(6): 1499-1511.

26. Manaster BJ (2013) Soft-tissue masses: Optimal imaging protocol and reporting. Am J Roentgenol 201(3): 505-514.

27. Panicek DM, Schwartz LH (1997) Soft tissue edema around musculoskeletal sarcomas at magnetic resonance imaging. Sarcoma 1(3-4): 189-191.

28. Sangkhathat S (2015) Current management of pediatric soft tissue sarcomas. World J Clin Pediatr 4(4): 94-105.

29. Yarmish G, Klein MJ, Landa J, Lefkowitz RA, Hwang S (2010) Imaging characteristics of primary osteosarcoma: nonconventional subtypes. Radiographics 30(6): 1653-1672.

30. Murphey MD, Walker EA, Wilson AJ, Kransdorf MJ, Temple HT, et al. (2003) From the archives of the AFIP: imaging of primary chondrosarcoma: radiologic-pathologic correlation. RadioGraphics 23(5): 1245-1278.

31. Chaabane S, Bouaziz MC, Drissi C, Abid L, Ladeb MF (2009) Periosteal chondrosarcoma. Am J Roentgenol 192(1): 1-6. 


\section{Clinical Radiology \& Imaging Journal}

32. Murphey MD, Arcara LK, Fanburg-Smith J (2005) Imaging of musculoskeletal liposarcoma with radiologic-pathologic correlation. Radiographics 25(5): 1371-1395.
33. Vilanova JC, Barceló J, Smirniotopoulos JG, PérezAndrés R, Villalón M, et al. (2004) Hemangioma from head to toe: MR imaging with pathologic correlation. RadioGraphics 24(2): 367-385. 